\title{
biologiatropical.org
}

\section{Entre el frío y bajo las sombras de El Salvador: Bolitoglossa synoria}

Roxana Margarita López-Martínez | Bióloga, M.sc. Oceanografía Biológica

BLOG 8 de septiembre de 2021

Existen muchas especies de salamandras en el mundo, pero particularmente hay una que está confinada a habitar únicamente en una pequeña fracción de bosque compartida entre en el norte de E1 Salvador y Suroeste de Honduras.

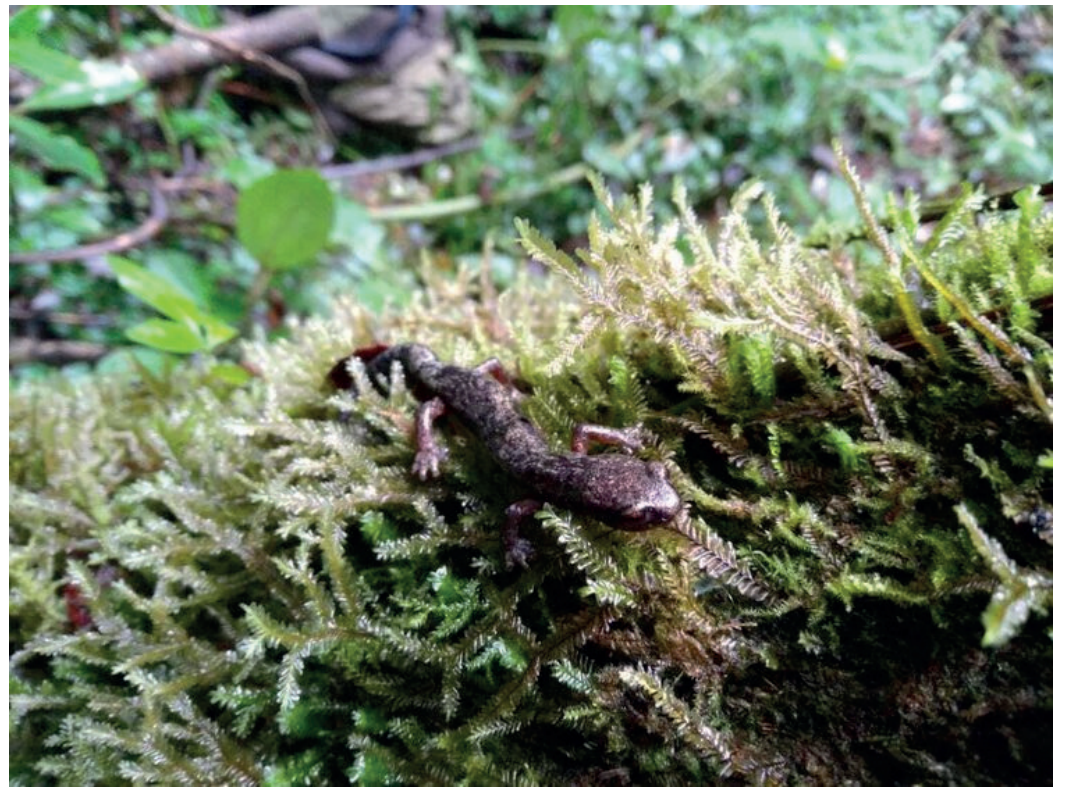

Bolitoglossa synoria de $8.1 \mathrm{cms}$, sobre vegetación en el Cerro El Pital, El Salvador. Fotografía: Wilfredo López.

A pesar de haber transcurrido más de 20 años de su descubrimiento para la ciencia, muy poco se sabe sobre la salamandra de El Pital y es que estos animales 
tienden a ser infravalorados y pasar desapercibidos para las exploraciones científicas y acciones de conservación, esto pese a su relevancia ecológica en el ciclaje de nutrientes e interacciones en los suelos de los bosques, además de ser controladores biológicos e incluso aliadas frente al Cambio Climático [1].

De forma general, los anfibios se encuentran en una crisis global que está conduciendo a su extinción.

Bolitoglossa synoria, es una salamandra de la familia Plethodontidae, es una especie de pequeño tamaño, que habita bajo troncos, hojarasca y sobre vegetación. Su existencia en el mundo se limita a una sola región, únicamente ha sido reportada para el punto más alto del El Salvador, en el Cerro El Pital (de ahí su nombre común) y para la Reserva Biológica El Pital en Honduras, ambos sitios corresponden a la misma zona geográfica, correspondiendo a áreas fronterizas de los dos países.

Aspectos relacionados a la reproducción de la especie, comportamiento y estado de sus poblaciones aún son enigmas sin resolver, esto, pese a que de acuerdo con la Unión Internacional para la Conservación de la Naturaleza (UICN) la cataloga como una especie en Peligro Crítico [2]. Además presenta amenazas 
crecientes para su conservación.

Actualmente una iniciativa en el pequeño país centroamericano pretende dilucidar parte de las interrogantes que giran en torno a la especie, así como tratar de disminuir las amenazas que enfrenta y que la conducen a una posible extinción. Gracias a la colaboración del MBZ Species Conservation Fund, el biólogo Raúl López en El Salvador lidera un proyecto de investigación y conservación para la especie [3], lo que está permitiendo que conozcamos más sobre ella y se generen herramientas que permitan el desarrollo de estrategias y acciones de conservación.

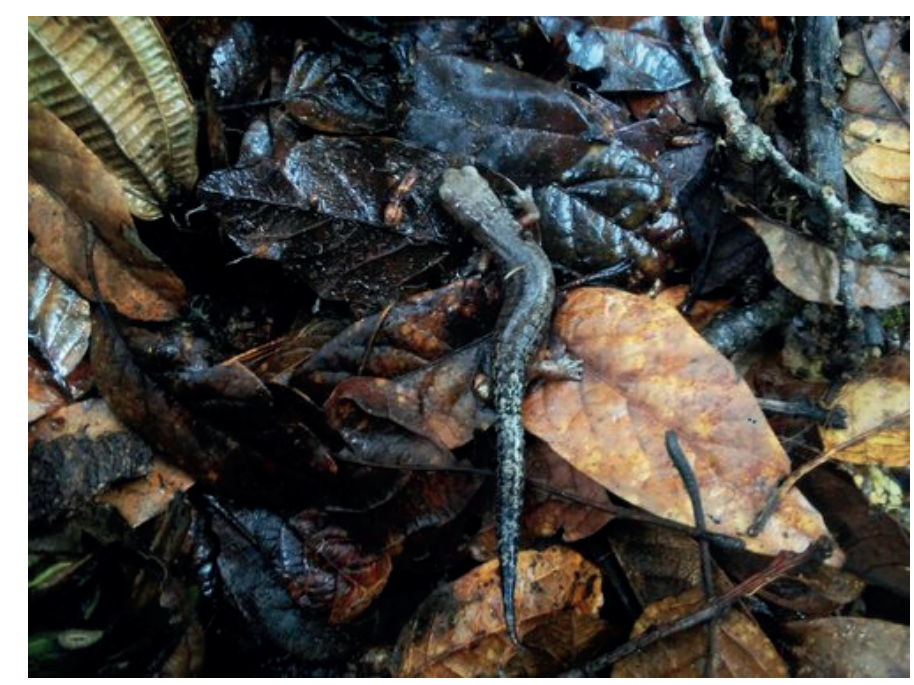

Bolitoglossa synoria, sobre hojarasca. Uno de los requerimientos del hábitat de la especie, es una abundante cobertura vegetal.

De forma general, los anfibios se encuentran en una crisis global que está conduciendo a su extinción [4], al no ser especies tan carismáticas como los grandes 
mamíferos pocos esfuerzos de investigación y conservación para ellos son realizados, haciendo inminente el declive de las poblaciones y pérdida de la biodiversidad. El fortalecimiento y manejo de espacios protegidos que presentan hábitat para las especies de anfibios como la salamandra de El Pital, regulaciones en torno al uso de agroquímicos y turismo, así como Educación Ambiental; son sin duda acciones en las que deben encaminárse los países de la región mesoamericana donde habitan gran parte de las especies del género Bolitoglossa.

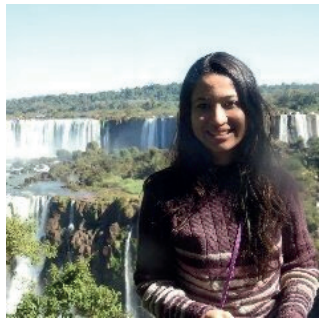

\section{Roxana Margarita López-Martínez}

Bióloga salvadoreña, maestra en oceanografía biológica por la Universidade Federal do Rio Grande (Brasil). Con experiencia en manejo y conservación de vida silvestre, ecología marina y ecotoxicología acuática. Investigadora y docente.

Correo electrónico: margarita.lopez91@outlook.com 


\section{REFERENCIAS}

[1] McLendon, R. 2017. Salamanders Take a Bite Out of Climate Change. (30/12/2020). Recuperado de https://www.treehugger.com/salamanders-take-a-bite-out-of-climate-change-4866224

[2] IUCN SSC Amphibian Specialist Group. 2020. Bolitoglossa synoria. The IUCN Red List of Threatened Species 2020: e.T59213A54376569. (28/12/2020). https://dx.doi.org/10.2305/IUCN.UK.20202.RLTS.T59213A54376569.en.

[3] The Mohamed bin Zayed Species Conservation Fund. 2020. Population assessment of the Bolitoglossa synoria amphibian of the Cerro El Pital Natural Area, El Salvador. (27/12/2020). Recuperado de https://www.speciesconservation.org/case-studies-projects/salamandra-del-pital/23919

[4] Betancur-Alarcón, L. 2015. Ranas, salamandras y sapos, los desprotegidos del mundo animal. (30/12/2020). Recuperado de https://www.eltiempo.com/archivo/documento/CMS-16423746

Editado por Katherine Bonilla. 